\title{
What do people know about eco-driving?
}

\author{
Article in Ergonomics · August 2016
}

DOI: $10.1080 / 00140139.2016 .1227092$

CITATION

1

\section{2 authors:}

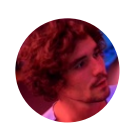

\section{Rich C Mcilroy}

University of Southampton

17 PUBLICATIONS 107 CITATIONS

SEE PROFILE
READS

143

Some of the authors of this publication are also working on these related projects: 


\title{
What do people know about eco-driving? An exploratory survey study
}

\author{
Rich C. McIlroy* \& Neville A. Stanton** \\ Transportation Research Group, Faculty of Engineering and the Environment, \\ University of Southampton, Southampton, S016 7QF, UK \\ *Corresponding author: r.mcilroy@soton.ac.uk \\ **n.stanton@soton.ac.uk
}

Acknowledgements

This research was joint-funded by the UK's Engineering and Physical Sciences Research Council (EPSRC), through the Transport and Environment programme, and Jaguar Land Rover PLC.

Published in the peer-review journal Ergonomics

The DOI of this paper is: $10.1080 / 00140139.2016 .1227092$. Once the article has published online, it will be available at the following permanent link:

http://dx.doi.org/10.1080/00140139.2016.1227092. 


\section{Abstract}

An online survey of 321 respondents revealed that the majority of people are aware of eco-driving and have a positive attitude towards it. Although the types of eco-driving tips offered by respondents, and their potential effect on fuelconsumption, were in line with those found in the popular and academic literature, knowledge of specific fuel saving behaviours was generally low. Relationships were found between environmental attitudes and knowledge of, and propensity to perform eco-driving behaviours; however, these relationships were weak, indicating that neither pro-environmental attitudes nor knowledge of eco-driving behaviours is strongly indicative of actual eco-driving performance. Males were found to be more knowledgeable of the means for driving in a fuel-efficient manner than females; however, no effect was found for either age or level of general education. Results are discussed in terms of the challenges and opportunities for encouraging eco-driving, and the necessity for both governmental and industry involvement.

Keywords: Eco-driving; environmental attitudes; environmental behaviours; energy use; behaviour change

\section{Practitioner Summary}

To successfully encourage the uptake of eco-driving (e.g. through policy, training and feedback) it is first necessary to understand how the general public perceives it, and what they already know of it. This survey study addresses this by looking at relationships between environmental attitudes and knowledge, and specific eco-driving measures. 


\section{Introduction}

Without effort on the part of all participants of society it is highly unlikely that we will see $80 \%$ lower $\mathrm{CO}_{2}$ emissions volumes in 2050 than those that were recorded in 1990 (the target put forward in the UK's Climate Change Act of 2008). Of course, improvements in technology (in all domains) have had, and will continue to have, significant effects on efficiency; however, technological advancement alone is not a sufficient strategy for climate change mitigation. Behavioural change is also required (e.g. Stern, 2006), hence the application of Ergonomics to the sustainability domain (e.g. Haslam \& Waterson, 2013; Thatcher, 2012). Intervention programmes to this effect have been well documented in the domestic setting (Abrahamse, Steg, Vlek, \& Rothengatter, 2005), and such schemes (alongside technological improvements) are likely to have contributed to the reduction in household energy use figures seen over the past 40 years in the UK (see Department of Energy and Climate Change, 2015).

This trend has not, however, been witnessed in the transport domain, with road transport, which accounts for $74 \%$ of the domain's emissions, being of particular concern (Department of Energy and Climate Change, 2015). The documented increase in energy use over the past two decades can be attributed to significant increases in the number of vehicle-kilometres driven each year (Transport, 2015). Indeed, to this end, encouraging the use of other forms of transport, e.g., cycling, walking, and public transport, is certainly a highly worthwhile topic for research and investment. Encouraging this form of behavioural change is, however, highly challenging (e.g. Stanton et al., 2012), with the private road vehicle often presenting the most convenient, if not the only, means for completing a given journey. This article therefore focuses on 
behaviours exhibited in the vehicle, with the ultimate aim of informing suitable means for encouraging efficient use of said vehicle.

\subsection{Eco-driving}

Eco-driving is the term for the set of behaviours and driving styles that characterise fuel-efficient driving (e.g. Barkenbus, 2010), and it has been suggested that the average driver could achieve fuel savings of around $10 \%$ simply by changing the way they drive (ibid.). Such behaviours include the avoidance of harsh accelerations, the performance of early gear changes, the avoidance of braking (through anticipation of the road environment), minimised peripheral use (e.g. air condition), and reducing drag at higher speeds (Ecowill, 2015; Hooker, 1988) Despite the fact that the effect of driving style on fuel use has been understood by the academic community for a considerable number of years (Evans, 1979; Waters \& Laker, 1980), there has been relatively little research into the general public's perception and understanding of eco-driving. Such an understanding would help academia, government, and industry to develop means for supporting such behaviours, be that through in-vehicle devices, policy interventions, or educational strategies. This exploratory, surveybased research therefore addresses this knowledge gap.

In terms of existing literature addressing this issue, three such studies stand out; Delhomme et al. (2013), in an analysis of the self-reported frequency and difficulty with which people exhibit fuel-efficient driving behaviours; Harvey et al. (2013), in an investigation of the fit between eco-driving attitudes and environmental attitudes more generally; and King (2011), in a study of people's pre-existing knowledge of specific eco-driving strategies. 
In Delhomme et al. (2013) respondents to a survey reported anticipation to be the easiest and most frequently adopted eco-driving strategy, and early gear changes and low motor revolution maintenance to be the most difficult. It was also found that those with higher environmental concern, and older drivers (particularly older females) reported lower difficulty in adopting fuel-efficient driving behaviours, and a higher frequency of performing them.

Where Delhomme and colleagues primarily looked at the link between environmental concern and the reported performance of eco-driving behaviours, Harvey et al. (2013) also investigated attitudes. In a survey of 350 respondents, the authors found no strong links between price, convenience, environmental attitudes or attitudes towards eco-driving. In contrast to Delhomme et al.'s finding, Harvey et al. found that environmental concern is not of high enough priority to affect driving behaviour, and that eco-driving is considered less important than convenience. Although respondents reported high concern for the environment, this concern was not reflected in self-reported behaviours. Moreover, though in-vehicle feedback was considered as having potential to encourage the uptake of eco-driving behaviours, they were argued to be insufficient on their own.

Finally, King's (2011) report of a survey of New Zealand Automobile Association (AA) members provides us with information regarding people's knowledge of eco-driving behaviours. It was found that older drivers were more able to provide eco-driving tips (i.e., descriptions of specific in-vehicle ecodriving behaviours), and that males were able to provide more valid tips than females. The most commonly reported behavioural strategy related to light accelerations and braking; however, the survey also included behaviours 
performed outside of the vehicle (e.g., maintenance, weight reduction, tyre inflation) despite asking specifically for fuel-saving behaviours performed while driving. Moreover, tyre inflation was mentioned in the survey before asking respondents to provide fuel-saving tips; this very tip was the second most commonly reported. Knowledge of eco-driving was not, however, particularly high, with only around half of respondents providing two or more distinct fuelsaving tips, and only 50\% respondents referring to light acceleration and braking as good for fuel-economy. Self-reported propensity to perform those behaviours was also investigated; over $5 \%$ reported never following their own advice, and around $20 \%$ reporting doing so only sometimes.

The AA survey also looked at attitudes towards eco-driving, finding that although it is generally popular (with 88\% support), people were more interested in learning defensive driving, with fewer than $5 \%$ of respondents being prepared to invest a realistic sum in driver training (King, 2011).

These three investigations provided the starting point for the current research, namely the investigation of the general public's general perceptions of eco-driving, of their knowledge of specific eco-driving strategies, and of the relationships between general environmental attitudes, eco-driving knowledge, and the self-reported propensity to perform eco-driving behaviours.

\subsubsection{Perceptions and self-reported ability}

The first research question we address is an open one; what perceptions do people have of eco-driving? This question will be addressed in terms of two primary sub-questions, 1) whether people think it is a good idea in general; and 2) the potential fuel-savings that could be achieved by themselves and by the 
'average' driver. This second question replicates that reported by King (2011), and relates to the finding that people consider themselves to already be more efficient than the 'average' driver. Such over-confidence in one's own ability is a stable finding in psychology (Alicke, Klotz, Breitenbecher, Yurak, \& Vredenburg, 1995; Alicke, 1985), and has previously been demonstrated in the driving domain (McKenna, Stanier, \& Lewis, 1991; Svenson, 1981).

Whether or not estimates provided by the general public reflect those seen in the academic literature (Barkenbus, 2010) is also of interest. If people consider the effect to be insignificantly small, they may be less likely to think it worthwhile; however, if they assume the effect to be greater than is likely to be the case, they may become frustrated with their (perceived) lack of success and give up the practice altogether.

\subsubsection{Knowledge, attitudes, and behaviour}

The second research question is also exploratory, again reflecting King's (2011) line of enquiry; what do people know of eco-driving, and are they aware of their levels of knowledge? Specifically, when asked to provide eco-driving tips, which behavioural strategies are most commonly reported, how many different behavioural strategies do people report, and do the reported strategies correspond to those present in the literature?

Relatedly, does self-reported knowledge correspond to actual knowledge? In other words, do people's self-rated knowledge of eco-driving on a scale (i.e., from "never heard of it" to "confident how to do it") correspond to a quantitative measure of eco-driving knowledge? Early research from Lichtenstein and 
Fischhoff (1977) indicates that people are generally good judges of their own knowledge, but that judgements are prone to biases of over-confidence.

The third research question concerns the possible link between attitudes and knowledge, asking whether or not those with more pro-environmental attitudes also hold more knowledge of specific eco-driving behaviours. A consistent and positive (although relatively weak) relationship between environmental knowledge and attitudes has been found in the past (Arcury, 1990; Flamm, 2006). Does this extend to eco-driving knowledge? Specifically, are those with more pro-environmental attitudes also more knowledgeable in terms of specific fuel-saving, in-vehicle behaviours (i.e., able to provide more valid ecodriving tips)? Following Arcury and Flamm, we hypothesise that those with more pro-environmental attitudes will also be more knowledgeable of eco-driving behaviours.

The fourth research question concerns the relationship between attitudes and behaviours. It has been demonstrated that those with more proenvironmental attitudes are also likely to report engaging in more proenvironmental behaviours (e.g. Bamberg \& Möser, 2007); does this extend to eco-driving behaviours? Specifically, do those with more pro-environmental attitudes also report a higher propensity to perform specific in-vehicle, ecodriving behaviours? Regarding this, we hypothesise that those with more proenvironmental attitudes will also report a higher propensity to perform ecodriving behaviours.

The fifth research question considers the relationship between knowledge and behaviour. Greater knowledge of potential action strategies has been shown to be associated with higher self-reported performance of pro- 
environmental behaviour (Hines, Hungerford, \& Tomera, 1987); again, does this extend to eco-driving specifically? That is to say, do those people more knowledgeable of the means for driving efficiently (i.e., able to provide more valid eco-driving tips) also report performing those behaviours? Given the Hines et al.'s finding, we hypothesise that those who are more knowledgeable of ecodriving behaviours will also report a higher propensity to perform them.

\subsubsection{Gender, age, and education}

As aforementioned, in Delhomme et al. (2013) older, female drivers were found to report a higher likelihood of adopting eco-driving behaviours; however, in King (2011), it was demonstrated that older, male drivers held more knowledge of eco-driving behaviours. Research question six therefore addresses gender and age differences. With regard to gender, the question is left open; however, given the two results described above, we hypothesise that older drivers will hold more knowledge of eco-driving behaviours than younger drivers, and will report a higher propensity to perform those behaviours.

In terms of education, Diamantopoulos et al. (2003) found that individuals with higher levels of general education also had higher levels of environmental knowledge, particularly for those with degree level qualifications (e.g., BA, BSc). Hence the seventh research question asks if this relationship is also true for eco-driving knowledge specifically. Here we hypothesise that individuals with higher levels of education will also hold more knowledge of ecodriving. 


\subsection{Summary of purpose}

As aforementioned, the ultimate aim of this research is to inform the design of suitable means for encouraging eco-driving, via the acquisition of information regarding people's knowledge and perceptions of the practice. Understanding what people already know of eco-driving and what they think of it, and how these variables relate to demographic factors and environmental attitudes, may help to inform potential future investment decisions, be that via training, educational initiatives, policy change, or technological development (e.g. in-vehicle devices). We therefore pose the following research questions (summarised from above):

Q1. What perceptions do people have of eco-driving and its effects? Q2. What do people know of eco-driving (i.e., of the specific behaviours)? Q3. Are more pro-environmental individuals more knowledgeable of the means for eco-driving?

Q4. Do more pro-environmental individuals report performing ecodriving behaviours to a greater extent than less pro-environmental individuals?

Q5. Do people with greater knowledge of eco-driving also report performing it to a greater extent?

Q6. How does knowledge of, and propensity to perform eco-driving behaviours vary with age and gender?

Q7. Do those with higher levels of general education also have more knowledge of eco-driving behaviours?

\section{Survey}

The questionnaire was administered online through the University of Southampton's iSurvey online questionnaire tool, and consisted of three main sections, in the following order; 1) demographics, 2) eco-driving awareness, 
knowledge, and perceptions, and 3) environmental attitudes. Demographics questions included age (18-24, 25-34, 35-44, 45-54, 55-64, 65 or over), gender (male or female), and level of highest completed education (GCSE or equivalent, A level or equivalent, undergraduate degree, postgraduate degree, none of the above), and asked whether or not individuals had received additional or advanced driver training (yes or no). This section also asked participants the number of years they had held a licence, the amount driven annually, and whether or not they currently had access to a vehicle.

\subsection{Eco-driving section}

\subsubsection{Perceptions}

In the eco-driving section, participants were first told "the way in which a car is driven affects the amount of fuel consumed per mile". They were then asked to provide estimates of this effect for others ("about how much difference do you think this 'driving behaviour' can have for the average person?") and for themselves ("what kind of effect do you think it could have for your fuel use?"). Eight possible responses were offered for each of the two questions; $0-5 \%, 5$ $10 \%, 10-15 \%, 15-20 \%, 20-25 \%, 25-30 \%, 30-35 \%$, More than 35\%. Participants were then asked "have you heard about the practice of 'eco-driving'?" and "what do you think of 'eco-driving'?"; possible responses are displayed in Figures 2 and 3 in results section 3.3.1.

\subsubsection{Knowledge}

In order to assess knowledge of the specific means for driving in a fuelefficient manner (in a way that would be less prone to self-report biases than 
simply asking participants of their level of eco-driving knowledge), a line of questioning identical to that used by King (2011) was adopted. The section also assessed the participants' self-reported tendency to perform such behaviours. Participants were first asked "Could you give a tip for reducing fuel consumption while driving?" (answers given in free text), followed by the question "How often do you follow this advice?", the five responses to which ranged from "never or almost never" to "always or almost always". This pair of questions was repeated four times (with the additional word 'another' for the second, third and fourth). The participant was told to skip each question if not able to provide an ecodriving tip.

\subsection{Environmental attitudes}

The third section assessed participants' environmental attitudes, and was taken directly from Harvey et al. (2013). Each of the 26 questions asked the participant to what extent they agreed with a given statement, with possible responses given on a 7-point Likert scale, ranging from 'strongly disagree' to 'strongly agree' (Harvey et al., 2013). All questions are displayed in Table 4, alongside results (section 3.2.2).

\subsection{Participants and ethics}

The sample was obtained in an opportunistic fashion; respondents were recruited through social media (e.g. Facebook, Twitter), email, and paper flyers (indicating the web address of the survey) distributed around the Southampton area (in particular the University of Southampton). The snowball approach was used, relying on friends, family and acquaintances of the authors to pass on 
physical flyers, emails, and web-links. Ethical approval was sought from, and granted by the University of Southampton's Ethics and Research Governance committee, reference number 11243 . Only those 18 years or over, who had held a full driving licence for at least one year, were asked to participate.

\section{Results}

Three hundred and twenty one people responded to the survey. Three hundred and eleven respondents are summarised, in terms of age and gender, in Table 1, alongside group percentages as proportions of the total sample size (i.e., 321). Ten participants did not provide age or gender information, corresponding to $3.1 \%$ of the sample. Only six respondents aged over 65 completed the survey (three male, three female); this group was therefore combined with the 55-64 group for all subsequent analyses, forming a '55 and over' group (reflected below in Table 1).

Table 1 . Age and gender groups of the 311 respondents to these questions

\begin{tabular}{ccccccc}
\hline & & \multicolumn{4}{c}{ Age group } \\
& & $18-24$ & $25-34$ & $35-44$ & $45-54$ & 55 and over \\
\hline \multirow{3}{*}{ Gender } & Female & $18(5.6 \%)$ & $62(19.3 \%)$ & $19(5.9 \%)$ & $25(7.8 \%)$ & $36(11.2 \%)$ \\
& Male & $27(8.4 \%)$ & $67(20.9 \%)$ & $19(5.9 \%)$ & $19(5.9 \%)$ & $19(5.9 \%)$ \\
\hline
\end{tabular}

The number of years with a driving licence ranged from 1 to $55(\mathrm{M}=$ $18.69, \mathrm{SD}=12.91)$, with 31 respondents stating that they did not currently have access to a vehicle. As may be expected from the sampling approach (i.e., university-centric) the average highest finished education level was higher in the 
sample than would be expected in the general population; 5 reported no qualifications, 25 at GCSE or equivalent, 54 at A level or equivalent, 124 undergraduate degree or equivalent, and 112 at postgraduate degree or equivalent. One respondent did not answer this question. Four respondents stated that driving constituted the main part of their job, and 67 as a part of their job (but not the main part); the remainder did not drive for their work. The survey also attracted 5 fleet drivers (though 11 did not answer this yes or no question), 76 drivers with extra training (7 did not answer this question), and 16 drivers belonging to motoring organisations (4 did not answer this question).

\subsection{Data reduction}

\subsubsection{Eco-driving knowledge}

Of the 321 respondents, 60 did not provide any tips in the eco-driving knowledge section, corresponding to $18.7 \%$ of the sample. The remaining 261 respondents provided 723 distinct tips (provided in free text); these were coded according to the coding scheme presented in Table 2 . The coding scheme was predominately developed from the responses themselves (i.e., iteratively); however, it was also informed by a general understanding of the behaviours that most influence fuel-efficiency, developed through reviews of popular literature (from sites such as www.ecodrive.org), and the academic literature (Barkenbus, 2010; Hooker, 1988). 
Table 2. Breakdown of categories, with examples from responses

\section{Code Example from survey responses}

Correct gear choice and rev minimisation "Drive in higher gears"

Gentle acceleration and braking - General "Plan your braking, brake gradually and accelerate gradually"

Gentle acceleration and braking Acceleration specific

"Do not accelerate too fiercely"

Gentle acceleration and braking Deceleration specific

"Reduce speed gradually instead of braking sharply"

Avoidance of acceleration and braking General

"Slowing the car without braking where possible and safe"

Avoidance of acceleration and braking "Use momentum and gravity e.g. coasting, de-clutching down Use of momentum hills etc."

Avoidance of acceleration and braking Anticipation of traffic

"Look and plan ahead so you can drive progressively by timing your arrival with gaps in traffic"

Avoidance of acceleration and braking Anticipation of road environment

"Cruise to junctions instead of hard braking"

Valid

Drag reduction "Don't drive with windows open"

Avoid excessive speed "Reduce average motorway speed to $60 \mathrm{mph}$ "

Minimise peripheral use "Turn off the air con"

Avoiding idling "Turn off the engine at long waits e.g. level crossings"

Tyre inflation "Keep tyres inflated"

Weight reduction "Take the rubbish out of your boot"

Engine tuning and maintenance "Ensure engine is well-maintained"

Route planning "Take the car for multiple tasks/multiple people in one journey"

Slow driving "Drive slowly"

Invalid

Avoid car use "Walk when possible, or ride a bike"

Other "Don't listen to loud rock music" 
The questions in this section specifically asked about saving fuel "while driving"; however, in the popular eco-driving literature (Ecowill, 2015; Energy Saving Trust, 2015; The AA, 2015) strategies such as proper tyre inflation, route planning, weight and drag reduction, and engine maintenance, all commonly appear as eco-driving tips. Therefore, despite not being behaviours that can be performed while driving, they have been included here as valid eco-driving tips. Not only do they have significant effects on fuel economy, but they are also commonly reported as eco-driving behaviours in the types of easily-accessible media to which the majority of respondents could have been exposed.

The reader will note that speed choice was split into two categories in Table 2, one valid, and one invalid. This reflects the fact that simply driving slowly is not an eco-driving behaviour in and of itself; it is the avoidance of excessively high speeds, particularly on motorways (where high speeds are expected), or the maintenance of an optimum speed (usually stated at around 45 to $50 \mathrm{mph}$; e.g. Barth \& Boriboonsomsin, 2008), that represent eco-driving strategies. Unqualified statements referring to slow driving were therefore considered invalid. Statements suggesting compliance with speed limits were also coded under this invalid speed category. Not only is compliance with road laws expected (hence not considered an additional fuel-saving strategy), but also it does not usually save fuel (e.g., driving at $60 \mathrm{mph}$ on a UK motorway is more efficient than driving at the $70 \mathrm{mph}$ speed limit, and $45-50 \mathrm{mph}$ is the most efficient speed regardless of the posted limit).

Advice related to the avoidance of car use altogether (e.g. "cycle, walk or use public transport where possible") was also coded as invalid. The questionnaire expressly discussed fuel efficiency and car use; although avoiding 
car use is arguably the most effective strategy for minimising fuel consumption, it is not an eco-driving tip.

Repeated advice was normally coded as invalid insofar as if a respondent provided more than one tip under a single code (e.g., two tips related to gear changes) only one of those was accepted. However, the two acceleration and deceleration codes ('gentle acceleration and braking' and 'avoidance of acceleration and braking') were each split, the first into two sub-divisions, the second into three; this allowed recognition for responses specifying different aspects of the same general class of behaviour. One individual (the principle author) coded all provided tips.

In order to test the coding scheme, 72 (approximately 10\%) of the distinct tips were chosen at random for inter-rater reliability testing. Tips coded as invalid due to repetition were replaced with another tip chosen at random. The final 72 tips were given to two other researchers, both personally known to the principal author (both were based in the same Human Factors research unit at the University of Southampton). Neither was involved in the research project in any other way. Following a short training session on the coding scheme, each researcher independently coded the 72 segments (assigning one category to each). Percentage agreement between the principle author's assignments and those of the first additional coder was 90.3\%. Cohen's Kappa was calculated, returning a value of $0.89(p<.001)$, indicating a very good agreement (Altman, 1991). The calculations made to compare responses of the principle author with the second additional coder revealed identical statistics; $90.3 \%$ agreement and a Cohen's Kappa of $0.89(p<.001)$. Each principal author / additional coder pairing saw seven disagreements; however, only one of these was common to 
both. The tip "change gear around 4,500 revs in a petrol vehicle", coded as incorrect by the principle researcher (advice suggests changing gear between 1,500 and 2,500 rpm), was coded under the 'gear change and rev minimisation' category by both additional coders.

In an attempt to quantify eco-driving knowledge (in order to arrive at an eco-driving 'score' for each participant) each eco-driving tip was scored in terms of the potential effect of the described behaviour on fuel economy. The effect of a given behaviour on the efficiency of a vehicle will, of course, depend on a multitude of factors, for example vehicle type, road topography, and traffic conditions. Furthermore, estimates vary across the literature; for example, estimates for the effect of 'aggressive' driving on fuel use ranges from $25 \%$ (Sivak \& Schoettle, 2011) to 41\% (De Vlieger, 1997). For the purposes of obtaining a general eco-driving knowledge 'score', however, absolute values are less important than relative values. The purpose of the score was to assess people's eco-driving knowledge relative to other respondents, rather than relative to actual fuel-efficiency values (which are themselves highly dependent on context). Work by Sivak and Schoettle (2011) was therefore used to guide scoring, as these authors provide estimates for nine of the eleven valid categories outlined in Table 2.

To have these estimates come from the same research effort, rather than across various articles, reduces potentially confounding effect of differences in measurement techniques or test vehicles. Sivak and Schoettle do not, however, provide estimates for the effect of optimal gear choice and engine revolution (rev) minimisation, nor for aerodynamic drag, and we could find no single article providing estimates for all eleven categories. Values assigned to these two 
categories were therefore taken from other sources (see Table 3). We recognise this as a potential limitation of the scoring system.

For gear choice and rev minimisation, Beckx et al. (2007) provide an estimate of $30 \%$ for the difference in fuel consumption between 'normal' and 'aggressive' gear change assumptions, averaged across an entire journey. For the effects of aerodynamic drag, Haworth and Symmons (2001) provide an estimate of $10-15 \%$ for vehicles travelling at high speeds. The lower end of this estimate has been used as the score for this category in order to reflect the potential savings made across an entire journey rather than for a section of a journey (in line with other categories). Regarding the 'gentle acceleration and braking' and 'avoidance of acceleration and braking' categories, participants were only assigned a score for each of the sub-categories provided they had not already provided a 'general' comment for that category. Generous coding was, however, applied; if the respondent provided, for example, one general comment, and then one comment each for two different sub-categories, they were scored for two responses, i.e., they were given the maximum allowable. All invalid tips were given a score of zero.

Finally, this section also asked about the respondents' propensity to follow their own eco-driving advice. In order to arrive at a single score for each participant the mean of the reported propensity values $(0=$ 'never or almost never', 4 = 'always or almost always') corresponding to each respondent's valid tips was calculated. Propensity scores for invalid tips were not included in the calculation. 
Table 3. Coding scheme, assigned scores, and sources from which scoring was developed

Potential fuel saving according to source

Description

Sivak \& Haworth \&

Schoettle Symmonds Beckx et al. Assigned

(Sivak \& (Haworth \& (Beckx et score

Schoettle, Symmons, al., 2007)

2011) 2001)

Gear choice / engine revs

$30 \%$

30

Gentle brake / acceleration

$25 \%{ }^{1}$

Avoid brake / acceleration

$25 \%^{1}$

25

Drag

$10-15 \%^{2}$

10

Speed

$6 \% 3$

6

Route selection

$6 \% 4$

6

Engine maintenance

$4 \%$

4

Peripherals

$4 \%^{5}$

4

Idling

$2 \%^{6}$

Tyre inflation

$1.5 \%^{7}$

Weight reduction

$1.5 \%^{8}$

1.5

\section{Notes:}

1. Saving refers to "aggressive driving" compared to good practice

2. Savings made at high speed

3. Savings made if optimal speed choice on motorways for $20 \%$ of the route

4. Savings if choosing one of two route options available for $20 \%$ of the total distance driven

5. Savings made when avoiding use of air-conditioning for $25 \%$ of distance driven 6 . Savings achieved by turning of engine during two 1-minute idle periods every 10 miles

7. Savings made compared to under-inflation of all four tyres by $5 \mathrm{psi}$

8. Savings made with 100 pounds ( $45.4 \mathrm{~kg}$ ) of excess weight removed 


\subsubsection{Environmental attitudes}

As aforementioned, the environmental attitudes section was taken directly from Harvey et al. (2013), the questions and results for which can be found in Table 4. Each of the 26 items invited the respondent to indicate, on a 7point Likert scale, the extent to which they agreed with a given statement (from 1, strongly disagree, to 7, strongly agree). Principal component analysis with varimax rotation was undertaken, resulting in the identification of four factors. Although Harvey et al. (2013) also reported four factors, our analysis resulted in different item groupings: F1, general energy use attitudes; F2, energy conservation attitudes; F3, incentives for energy use reductions; and F4, motivation to use public transport.

Factor 1 initially grouped items $2,4,6,7,8,19,21,24$, and 25, resulting in a Cronbach's alpha coefficient (hereinafter alpha; Cronbach, 1951) of .655; however, after removal of items 6, 19, and 25 (due to low item-total correlations) alpha for this scale rose to .666. Similarly, Factor 2 initially comprised items 1 , $10,11,15,16,18$, and 22 , resulting in an alpha of .653; removal of item 10 resulted in an alpha of .681. Factor 3's low alpha score (.626) could not be remedied by removal of any items. These reliability scores are not high (.7 usually being accepted as the lower threshold; Nunnally, 1978); however, the scale used here is a short one. Not only are high alpha values harder to achieve with shorter scales (e.g. Streiner, 2003), the .7 threshold itself (particularly when used for shorter scale lengths) has been questioned (Schmitt, 1996). These factors were therefore accepted; however, it is important to note that short scale 


\section{length does not alleviate problems of unreliability, therefore all following analyses made with Factor scores are done so with caution.}

Table 4. Post factor analysis Environmental Attitude section results

\begin{tabular}{|c|c|c|c|c|c|c|}
\hline Factors & F1 & $\mathrm{F} 2$ & F3 & $\mathrm{F} 4$ & $\begin{array}{l}\text { Item } \\
\text { Mean }\end{array}$ & Item SD \\
\hline \multicolumn{7}{|l|}{ F1: General Energy Use Attitudes } \\
\hline Q2: Need to find better ways to produce clean energy & .665 & .138 & .218 & -.075 & 6.41 & 0.88 \\
\hline Q4: We live in an energy guzzling society & .573 & .008 & .463 & -.118 & 6.04 & 1.03 \\
\hline Q5: Energy issues are over-rated & -.614 & -.067 & .050 & -.226 & 2.51 & 1.50 \\
\hline Q7: High energy-consumption is bad for the environment & .492 & -.004 & .119 & -.102 & 5.98 & 1.14 \\
\hline Q8: I do not see how we can make large reductions in fuel and energy use & -.547 & -.148 & .187 & -.160 & 2.91 & 1.56 \\
\hline Q14: Worry that gas and oil will run out in 30 years & .315 & .192 & .158 & .259 & 4.46 & 1.67 \\
\hline Q21: I would support congestion charges to help reduce traffic and pollution & .432 & .233 & .187 & .224 & 4.00 & 1.86 \\
\hline Q24: It's a waste of time to get people to use cars less & -.501 & .028 & .162 & -.421 & 3.52 & 1.70 \\
\hline \multicolumn{7}{|l|}{ F2: Energy Conservation Attitudes } \\
\hline Q1: Motivated to save money on energy at home & .280 & .586 & .144 & -.040 & 6.05 & .94 \\
\hline Q11: When I next buy a car, I will choose one with better fuel consumption & .189 & .453 & -.005 & .131 & 5.19 & 1.50 \\
\hline Q15: At home, like to get cheapest energy possible & -.173 & .675 & -.002 & -.107 & 4.71 & 1.54 \\
\hline Q16: Try to reduce energy consumption at home & .186 & .744 & .070 & .153 & 5.73 & .98 \\
\hline Q18: Switch off lights wherever not used & .067 & .575 & .055 & .074 & 5.93 & 1.03 \\
\hline Q22: Wasting energy annoys me & .380 & .495 & .179 & .231 & 5.63 & 1.10 \\
\hline \multicolumn{7}{|l|}{ F3: Incentives For Energy Use Reductions } \\
\hline Q3: People at work don't care about saving fuel & -.104 & .051 & .684 & -.118 & 4.96 & 1.55 \\
\hline Q12: Energy prices must rise to sort out problems & .095 & .029 & .439 & .073 & 3.97 & 1.75 \\
\hline Q13: People will only change energy consuming habits if forced to & .190 & -.034 & .596 & -.003 & 5.17 & 1.44 \\
\hline Q17: People will only save fuel if they have an incentive & -.187 & .219 & .680 & .123 & 5.07 & 1.37 \\
\hline Q20: Traffic fumes in city centres bother me & .332 & .383 & .319 & .034 & 5.09 & 1.51 \\
\hline Q26: People care more about saving fuel at home than at work & -.072 & .207 & .583 & .300 & 5.90 & 1.05 \\
\hline \multicolumn{7}{|l|}{ F4: Motivation To Use Public Transport } \\
\hline Q9: I would travel on public transport if it were cheaper & -.053 & .075 & .026 & .775 & 4.76 & 2.01 \\
\hline Q23: I would travel on public transport if it were more convenient & .071 & -.080 & .153 & .831 & 5.68 & 1.57 \\
\hline$\alpha$ Coefficients & .666 & .681 & .626 & .695 & & \\
\hline \multicolumn{7}{|l|}{ Removed Items } \\
\hline Q6: My own contribution to saving fuel could be better & .310 & -.346 & .111 & .127 & 5.35 & 1.21 \\
\hline Q19: It's important to complete a journey as quick as possible & -.244 & -.154 & .145 & -.067 & 3.37 & 1.59 \\
\hline Q25: I would only buy an eco car if it were no more expensive than a normal & -.394 & .061 & .116 & .118 & 4.78 & 1.70 \\
\hline Q10: I like to keep check on my car's MPG & -.064 & .412 & .090 & -.069 & 4.76 & 1.92 \\
\hline
\end{tabular}




\subsection{Addressing research questions}

\subsubsection{Q1: What perceptions do people have of eco-driving and its effects?}

Respondents were first provided with the statement "the way in which a car is driven affects the amount of fuel consumed per mile". They were then asked about the size of this effect, for both themselves (personal effect), and for others (effect for population). One individual (of the 321 respondents) did not answer this question. Results are presented in Figure 1; here it can be seen that the estimated differences were higher for 'the average person' (effect for population) than for the respondents' own fuel use (personal effect). This suggests that respondents consider a change in driving style would result in larger differences in other peoples' fuel-efficiency measures than in their own. A Wilcoxon singed-rank test revealed this difference to be significant $(Z=-6.74, p<$ $.001)$

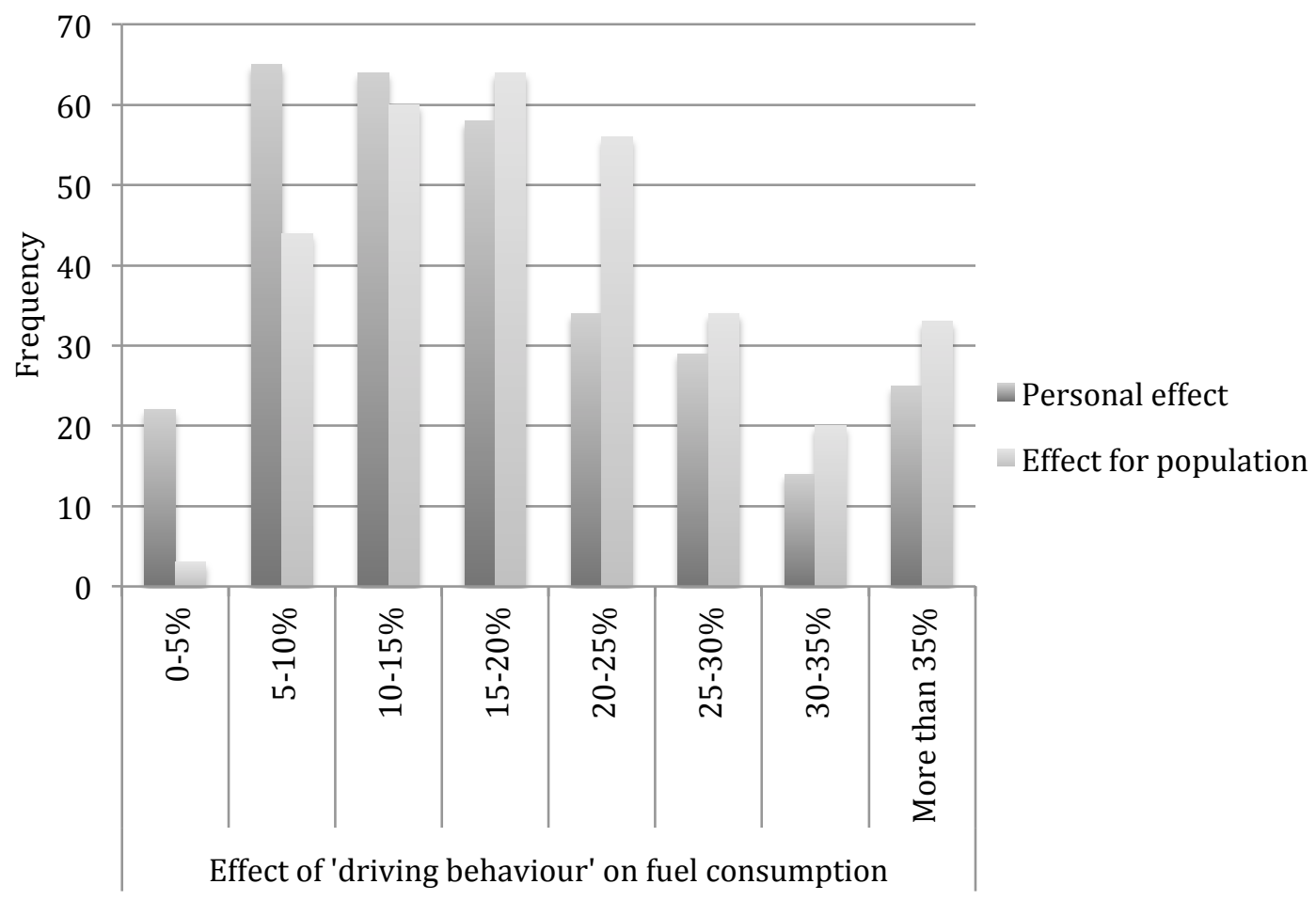

Figure 1. Frequencies of responses to statements regarding the effect of 'driving behaviour' on fuel consumption 
The term 'eco-driving' was then introduced, and the respondents asked about their knowledge and perceptions of the practice. Figures 2 and 3 display frequencies of responses to the two items regarding this question. All 321 respondents answered both of these questions (i.e., no missing data). Only one response was allowed for the question "Have you heard about the practice of 'eco-driving'?” (Figure 2). For the question “"What do you think of 'eco-driving'?" (Figure 3), the respondent was invited to tick all that apply.

Yes I know what it means and I am confident that I know how to do it Yes and I know what it means and I have an idea of how to do it

Yes I know what it means but don't know how to do it

Yes but I have only heard of it and am not sure what it means

No

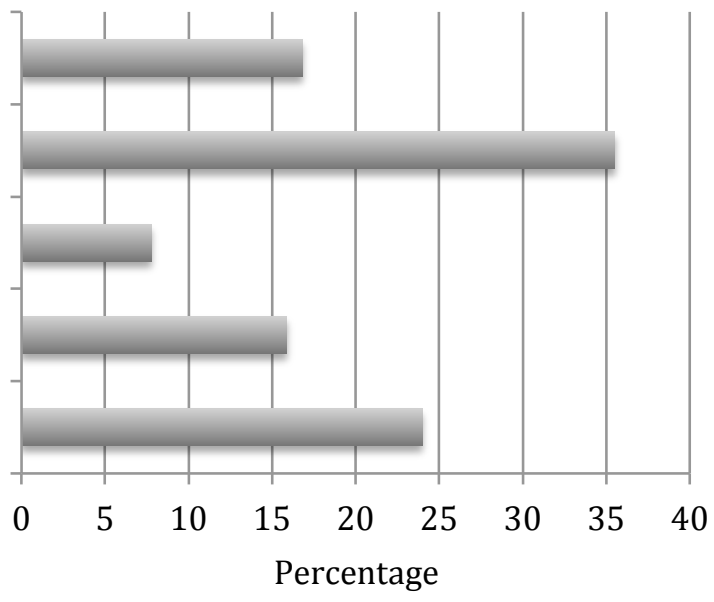

Figure 2. Percentage of responses to the question "Have you heard about the practice of 'eco-driving'?"

It is unsafe

Time pressure is more important than fuel

Reduces driving enjoyment too much

I'm too busy to worry about it

The UK / the world doesn't need it Helps drivers save money Good for the environment A good idea

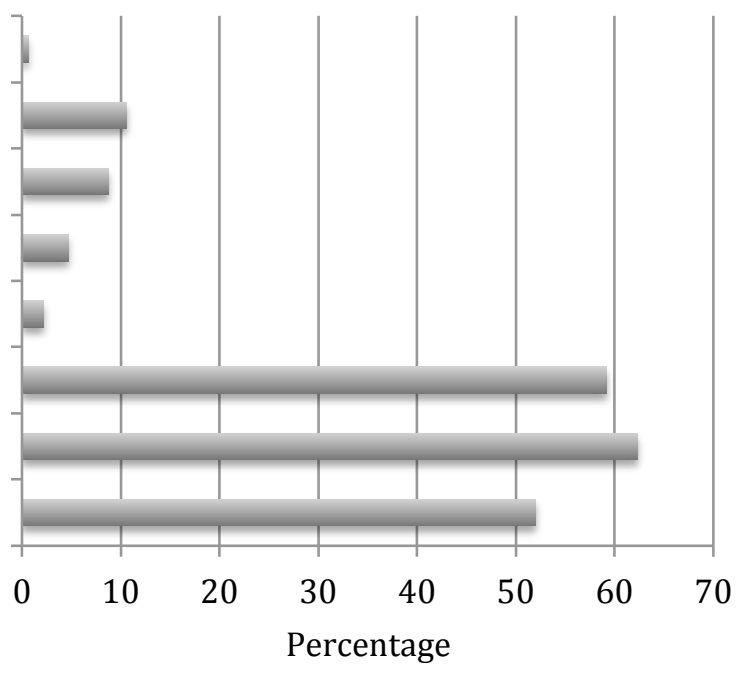

Figure 3. Percentage of respondents selecting answers to the question "What do you think of 'eco-driving'? (Please tick all that apply)" 
From Figure 2 it can be seen that of those that have heard of eco-driving, the majority state that they 'have an idea of how to do it' (114 individuals, 35.5\% of the total sample); however, 77 individuals (24.0\%) stated that they had not heard of it. From Figure 3 it is clear that the respondents generally consider ecodriving positively, with three lower options in Figure 3 receiving by far the greatest number of responses. Only two respondents considered the practice to be unsafe, and only seven selected "The UK / the world does not need it". However, 28 respondents indicated that eco-driving reduces driving enjoyment too much, and 34 indicated that time pressure is more important. Here, 75 individuals (23.4\%) stated that they had not heard of it.

\subsubsection{Q2: What do people know of eco-driving (i.e., of the specific behaviours)?}

As aforementioned, 261 of the 321 respondents (81.3\%) provided at least one eco-driving tip (including both valid and invalid tips), while 60 (18.7\%) did not provide any tips at all (i.e., they left this section blank). 46 individuals provided one tip (14.3\%), 63 provided two (19.6\%), 57 provided three (17.8\%), and 95 (29.6\%) provided four, the maximum possible. In total, 723 distinct tips were provided; 629 (87.0\%) of these were coded as valid, 94 (13.0\%) as invalid. 58 respondents (16.8\%) provided the maximum number of valid tips (i.e., 4 ), while 13 respondents (4.0\%) provided only invalid tips. Most of those offering at least one tip, however, provided no invalid tips at all (180 respondents, $56.1 \%$ ).

Regarding the types of tips most commonly provided, Figure 4 displays the frequencies with which each of the tip categories appeared. It can be seen that 'gear choice and rev minimisation' was the most commonly reported single category, with 112 individuals (34.9\%) offering tips under this category. When 
combining sub-categories (which are presented separately in Figure 5), we see 122 instances of the 'gentle acceleration and deceleration' category, and 154 instances of the 'avoidance of acceleration and deceleration' category. These do not, however, correspond to 122 and 154 respondents, as each respondent was able to provide a tip in each of the sub-categories without incurring a 'repetition' categorisation (see section 3.2.1). Only 109 respondents (34.0\%) provided one or more tips under the 'gentle accelerations and decelerations' category, and 131 respondents (40.8\%) provided one or more tips under the 'avoid acceleration and deceleration category'. This final category therefore represents the type of eco-driving advice reported by the greatest number of respondents. Of the invalid tips, 'slow driving' was referred to most often; 38 respondents (11.8\%) gave tips under this category. 


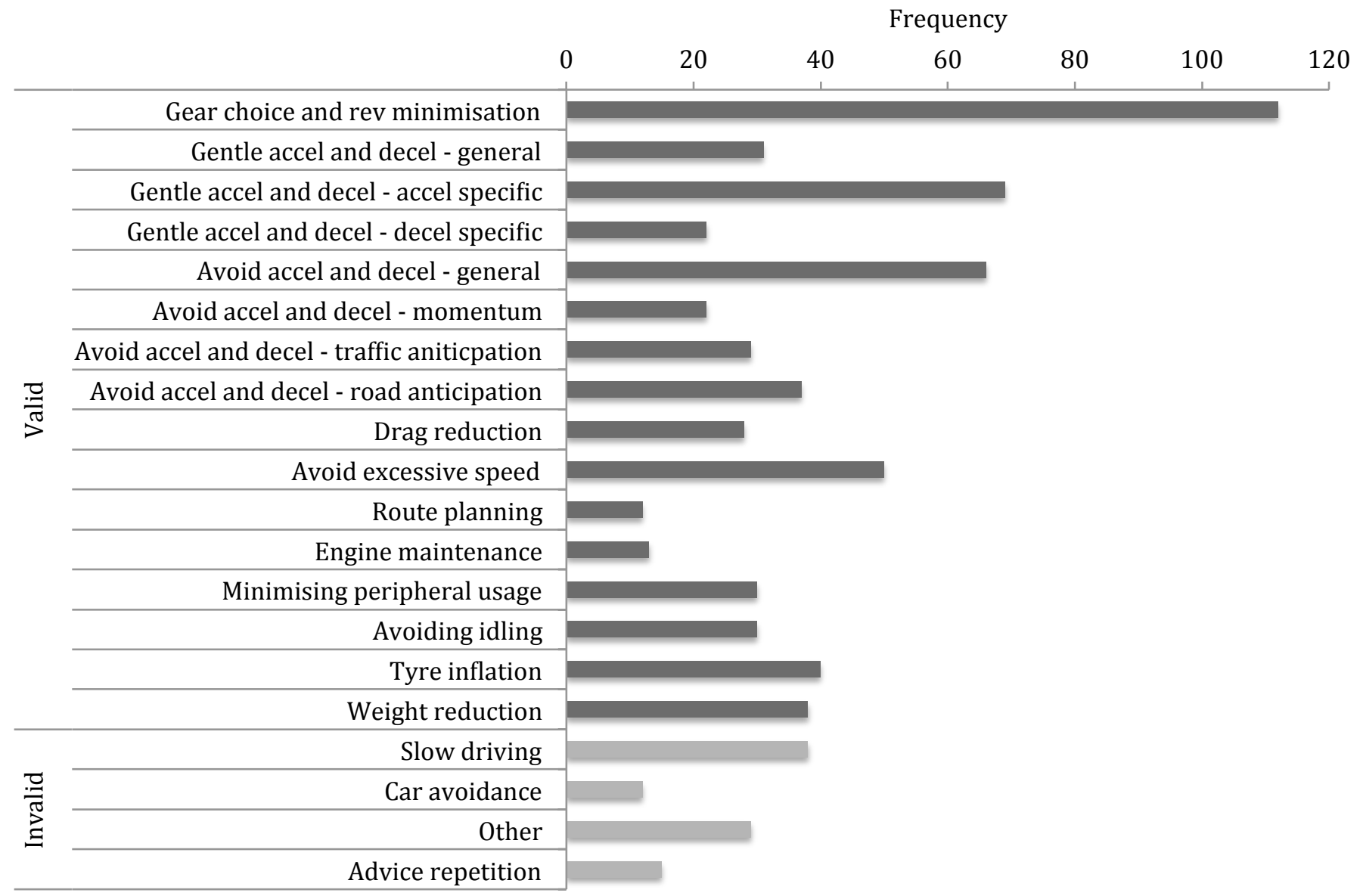

Figure 4. Frequency of tips, by category

With regard to tip score, values ranged from zero (for the 13 respondents providing only invalid tips, and the 60 providing no tips at all) to 105 , the maximum possible score (i.e., one gear choice comment, and three comments under the 'gentle acceleration and deceleration' or 'avoidance of acceleration and deceleration' categories). Three respondents (0.9\%) attained this maximum score. Mean tip score was $35.08(\mathrm{SD}=27.84)$.

To assess whether or not self-reported knowledge of eco-driving actually corresponds to measured knowledge, tip score (measured knowledge) was assessed in respect of respondents' answers to the question "Have you heard 
about the practice of 'eco-driving'?" (self-reported knowledge, with possible answers including "No", "Yes, but only heard of it", "Yes, but don't know how to do it", "Yes, and have an idea of how to do it", and "Yes, and confident how to do it"; see Figure 2, above). Of the 321 respondents, three did not answer the selfreported knowledge question, hence sample size for these calculations was 318. The Kruskal-Wallis test revealed significant differences in tip score between the five groups $(H=32.12, p<.001)$. Jonkheere's test revealed a significant trend in the data; tip score increased across answers from "No" to "Yes, and confident how to do it", $J=23,387, z=4.74, p<.001$. Differences between group means for those providing responses to first three options were, however, small. Those indicating that they have an idea how to perform the practice, or those confident of how to do it, scored significantly higher. Group means and standard deviations are presented in Table 5.

Table 5. Mean tip score grouped by responses to the statements "Have you heard of eco-driving?"

\begin{tabular}{cccccc}
\hline & No & $\begin{array}{c}\text { Yes, but only } \\
\text { heard of it }\end{array}$ & $\begin{array}{c}\text { Yes, but don't } \\
\text { know how }\end{array}$ & $\begin{array}{c}\text { Yes, and have } \\
\text { an idea how }\end{array}$ & $\begin{array}{c}\text { Yes, and am } \\
\text { confident how }\end{array}$ \\
\hline $\begin{array}{c}\text { Mean } \\
\text { SD }\end{array}$ & 27.54 & 24.13 & 24.77 & 43.77 & 44.33 \\
& 23.68 & 24.28 & 29.13 & 27.51 & 28.33 \\
\hline
\end{tabular}

\subsubsection{Q3: Are more pro-environmental individuals more knowledgeable of the} means for eco-driving?

Firstly, it is useful to note that agreement with the reality of the current global sustainability challenge was relatively high among the respondents; the majority of respondents agreed with the need to "find better ways to produce clean energy" ( $\mathrm{M}=6.41, \mathrm{SD}=0.88$, on a scale of 1 to 7$)$, and generally disagreed 
with the statement "energy issues are over-rated" $(\mathrm{M}=2.51, \mathrm{SD}=1.50)$. Furthermore, agreement with the statement "I am motivated to save money on energy consumption at home" was also high $(\mathrm{M}=6.05, \mathrm{SD}=0.94)$.

To assess relationships between environmental attitudes and eco-driving knowledge, normalised scores for Factors 1 and 2 ("general energy use attitudes" and "energy conservation attitudes"), for each respondent, were calculated (i.e., the average across the items in each scale). The relationships these variables had with tip score was then assessed using Spearman's $\rho$ (due to violations of normality, Pearson's $r$ was not used). Due to various combinations of missing data, the sample sizes for each of the three calculations (and those in subsequent sections) were slightly different (i.e., only full data sets were included in each calculation); sample size for each calculation is therefore presented. First, Factor 1 and Factor 2 were moderately correlated $(\rho=.37, p<.001, \mathrm{~N}=288)$. Factor 1 was significantly correlated with tip score; however, effect size was not high $(\rho=$ $.24, p>.001, \mathrm{~N}=294$ ). Similarly, Factor 2 was also significantly correlated with tip score, though again only weakly $(\rho=.21, p<.001, \mathrm{~N}=307)$.

\subsubsection{Q4: Do more pro-environmental individuals report performing eco-driving} behaviours to a greater extent than less pro-environmental individuals?

As aforementioned, to calculate a score indicating the general propensity to perform eco-driving behaviours (i.e., to follow one's own advice) the average of the respondents' individual propensity scores across all provided tips (from 0 = low propensity, to 4 = high propensity) was calculated. As described above, only propensity scores relating to valid tips were included in the calculation. The sample size therefore reduced to 248; propensity scores could not be calculated 
for the 13 respondents providing only invalid tips, nor for the 60 providing no tips at all. Mean propensity score was $2.99(\mathrm{SD}=0.78)$, with values ranging from zero to four.

Scores for Factors 1 and 2 were again used to investigate the relationships between environmental attitudes and the propensity to perform eco-driving behaviours. Using Spearman's $\rho$, it was found that Factor 1 scores did not significantly correlate with propensity scores $(\rho=.07, p=.310, \mathrm{~N}=232)$. A significant correlation was, however, found between Factor 2 scores and propensity score $(\rho=.24, p<.001, \mathrm{~N}=237)$.

3.3.5. Q5: Do people with greater knowledge of eco-driving also report performing it to a greater extent?

To address this question Spearman's $\rho$ was calculated for the relationship between propensity score and tip score; this revealed a significant but weak relationship $(\rho=.14, p=.035, \mathrm{~N}=248)$.

\subsubsection{Q6: How does knowledge of, and propensity to perform eco-driving} behaviours vary with age and gender?

To address this research question, two 2 (gender) x 5 (age; see Table 1 above) factorial ANOVAs were performed; one for tip score, the other for propensity score. Both sets of data met conditions of normality (visually checked using histograms) and equality of variance (Levene's test resulted in significance values of .943 and .365 for tip score and propensity respectively). For tip score, a main effect for gender was found; $F_{(1,301)}=18.30, p<.001$, partial $\eta^{2}=.057$. Subsequent pairwise comparison revealed that males $(M=43.19, S D=30.61)$ 
scored significantly higher than females $(\mathrm{M}=28.44, \mathrm{SD}=30.14 ; p<.001)$. No main effect for age was found $\left(F_{(4,301)}=0.35, p=.844\right.$, partial $\left.\eta^{2}=.005\right)$, nor was there a significant interaction effect $\left(F_{(4,301)}=0.75, p=.561\right.$, partial $\left.\eta^{2}=.010\right)$. Similar results were found for propensity scores; the 2x5 ANOVA revealed a significant main effect for gender $\left(F_{(1,229)}=11.46, p=.001\right.$, partial $\eta^{2}=$ $.048)$ but no significant main effect for age $\left(F_{(4,229)}=2.37, p=.053\right.$, partial $\eta^{2}=$ .040). For propensity, however, a significant interaction effect was found; $F_{(4,229)}$ $=3.12, p=.016$, partial $\eta^{2}=.052$. In terms of gender differences, a pairwise comparison revealed that males provided significantly higher propensity scores $(\mathrm{M}=3.18, \mathrm{SD}=0.73)$ than females $(\mathrm{M}=2.81, \mathrm{SD}=0.81)$. With regard to the interaction effect, this is represented in Figure 5. Greater differences between age groups for females than for males were observed; however, the non-linear trend in scores for females across age groups is not one that invites a simple explanation. 


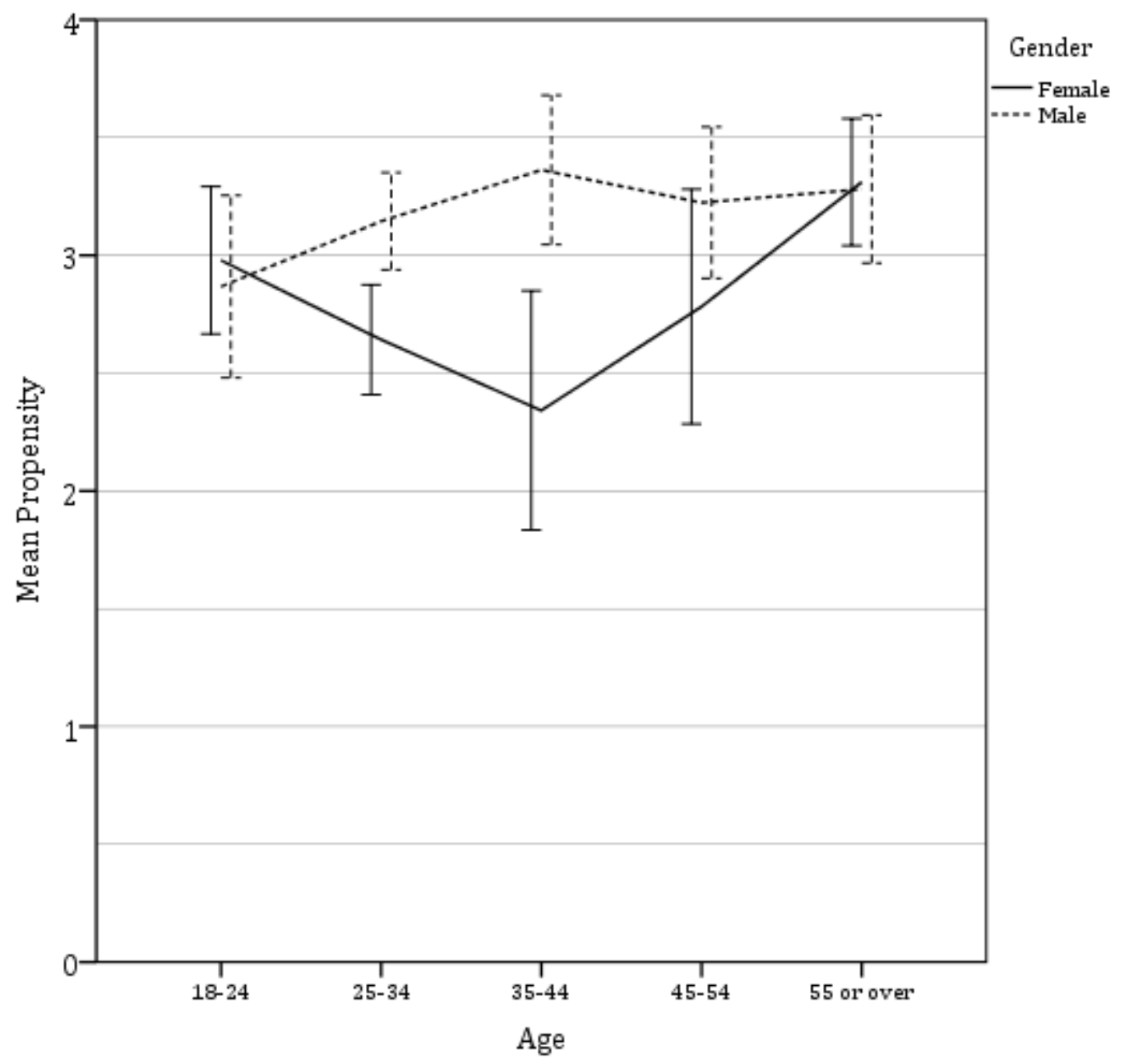

Figure 5. Interaction effect between age and gender for self-reported propensity to follow one's own eco-driving advice, with 95\% Confidence Intervals indicated

\subsubsection{Q7: Do those with higher levels of general education also have more} knowledge of eco-driving behaviours?

As data once again satisfied conditions of normality (visually assessed) and equality of variance (Levene's test resulting in a significance value of .180), a one-way ANOVA for tip score was performed to assess the relationship between tip score and general education across five groups (GCSE or equivalent, A level or equivalent, undergraduate degree, postgraduate degree, none of the above). This revealed no significant effects; $F_{(4,256)}=2.38, p=.052$, partial $\eta^{2}=.029$. 


\section{Discussion}

This survey study has attempted to address a variety of research questions, some of which were exploratory in nature, other of which invited specific hypotheses. Results will therefore be discussed in relation to each research question in turn.

4.1. Q1: What perceptions do people have of eco-driving and its effects?

Results suggested that, on the whole, people hold positive view of ecodriving, mirroring results from King's survey of New Zealand AA members (King, 2011). This positive result implies that people may be willing to adopt the technique given the right incentives. Many respondents indicated that the practice is not only good for the environment, but also that it helps drivers to save money. Hence any eco-driving encouragement incentives would do well to encapsulate both global environmental and personal financial benefits, rather than focus on one alone.

In King (2011) results indicated that people were more interested in learning defensive driving (for safety) than learning eco-driving techniques; however, the two have significant overlaps (e.g. Young, Birrell, \& Stanton, 2011). Very few respondents to our survey (only two) considered eco-driving as unsafe. We conclude, therefore, that safety concerns are not a barrier to eco-driving uptake; however, given the importance of safety in driving (a highly safetycritical domain), training a combination of the two approaches is likely to be beneficial. Indeed, to this end the Driver and Vehicle Standards Agency (DVSA; a UK governmental agency) already includes in its Official DVSA Guide to Driving 
(an industry-standard text recommended especially to learner-drivers) a full chapter on 'ecosafe' driving, the practice of safely minimising fuel consumption in the vehicle (Driver and Vehicle Standards Agency, 2015). However, according to a report from the Driving Standards Agency (the pre-2014 name for the DVSA), criticism has been voiced regarding the way in which eco-driving is included in the standard driving test, particularly with regard to consistency (Campbell-Hall \& Dalziel, 2011). This report also suggested that post-licence training specifically focussing on eco-driving was not only rarely offered, but was more difficult to sell than training offering eco-driving tips alongside other advanced driving content. A more suitable method to train efficient drivers may therefore be to stress the overlaps between safe and efficient driving (Young et al., 2011). Such an approach may also satisfy respondents to King's (2011) survey; here, the training of defensive driving was seen as more desirable than the training of eco-driving techniques (though see also Delhomme et al. (2010) for an argument for using environmental protection concerns to encourage safer driving).

Regarding the potential effect of driving behaviour on efficiency i.e., the savings that can realistically be achieved by altering ones driving style, respondents' estimates were largely in accordance with the $10 \%$ posited in the literature (Barkenbus, 2010), at least for the effect that the practice would have on their own fuel consumption. In terms of the effect that the practice would have on other drivers' efficiencies, respondents stated that it would have a larger effect. This could be indicative of the oft-cited over-confidence bias (Alicke et al., 1995; Alicke, 1985); people may consider themselves to already be more efficient than the average driver, and therefore have less room for improvement 
(as was suggested by results in King, 2011). An alternative explanation, however, is that people think that other drivers may be more successful at eco-driving, and thereby achieve greater savings. Further study would be required to untangle this issue; however, regardless of the underlying reason for this result, the difference in estimates is important for any eco-driving education or advertisement programme, as it implies that care should be taken to stress the effectiveness for all drivers, regardless of how they currently perceived themselves. For example, when given accurate information about the performance of others, over-confidence effects are attenuated (e.g. Moore \& Small, 2007).

4.2. Q2: What do people know of eco-driving (i.e., of the specific behaviours)?

In King (2011) the most commonly reported eco-driving tip was in relation to light accelerations and braking. Results from our survey repeat this finding, although more specifically regarding the avoidance of accelerations and decelerations (a further specification not made in King's research). Furthermore, gear choice and rev minimisation also featured highly. These three most commonly reported categories reflect the relative importance of each behaviour in terms of their effects on fuel consumption as reported in the literature (Barkenbus, 2010; Hooker, 1988; Sivak \& Schoettle, 2011), suggesting that those able to provide eco-driving tips are generally aware of the behaviours that most influence fuel efficiency.

Furthermore, these categories also generally reflect those found by Franke et al. (2016) in their interview study of highly efficient Toyota Prius drivers. Although their study focussed on the challenges brought specifically by 
hybrid vehicles, many of the eco-driving strategies were the same as those offered by respondents to our research. However, whereas Franke et al.'s participants could be considered as experts in fuel-efficient driving (i.e., they were recruited from an on-line fuel-monitoring website, and each recorded above average efficiency values), respondents to our survey were not. It is perhaps unsurprising, therefore, that the absolute numbers of respondents providing valid eco-driving advice was quite low. Fewer than half of the respondents mentioned gear choice or rev minimisation as an influencing behaviour, with similar findings for both gentle accelerations and decelerations and avoidance of accelerations and decelerations. This suggests that education and training will have an important role to play in encouraging eco-driving; one cannot perform a pro-environmental behaviour without first knowing the possible action strategies that are available (Hines et al., 1987; Jensen, 2002).

The results presented above also indicate that people are aware of their own levels of knowledge, at least in a relative sense (Lichtenstein \& Fischhoff, 1977). That is to say, the trend in tip score across respondents was also seen across self-reported knowledge of eco-driving; those who think they are more knowledgeable do indeed score more highly (on tip score) than those who think themselves less knowledgeable. For training and education purposes this is important, as when judging where incentives should be focussed (e.g., training or education) it may be sufficient to simply ask people how much they know of ecodriving, rather than assessing knowledge via some form of test. This result does not, however, tell us about absolute knowledge, and as the group means in Table 5 show, even those in the two higher scoring groups (i.e., those how answered that they had an idea, or were confident, of how to eco-drive) still achieved a tip 
score (on average) considerably lower than the maximum possible. Hence, although some may be more deserving of eco-driver training or education than others, such a scheme would likely benefit all participants.

4.3. Q3: Are more pro-environmental individuals more knowledgeable of the means for eco-driving?

In order to measure the relationship between eco-driving knowledge and pro-environmental attitudes, only Factors 1 and 2 of the environmental attitude section were used ('general energy use attitudes' and 'energy conservation attitudes'). Factor 3 was not employed as not only was the reliability of this scale quite low (with a Cronbach's alpha of 0.626 ), but also it related more to opinions on incentives for energy reduction rather than on general energy use and conservation attitudes. Factor 4 was not used as this only dealt with motivations to use public transport. Moreover, it is worth pointing out again that the four factors we identified here were different to those identified by Harvey et al. (Harvey et al., 2013) in their use of the same questionnaire. It is therefore more difficult to make comparisons between the results of our study and those of Harvey et al. (ibid.). That general energy use attitudes and energy conservation attitudes are significantly related was, however, a general finding common to both our results and those of Harvey et al. (ibid.). In terms of the relationship these two factors have with eco-driving knowledge, although the two correlations were significant, effect sizes were weak. This reflects Arcury's (Arcury, 1990) finding of a weak relationship between environmental knowledge and attitudes (Flamm, 2006). We therefore tentatively accept our hypothesis that those with more pro-environmental attitudes are also more 
knowledgeable of the means for eco-driving; however, with the caveats of a weak effect size, and the potential problems associated with relatively low-reliability scales (i.e., Factor 1 with an alpha of 0.666 , Factor 2 with an alpha of 0.681 ).

4.4. Q4: Do more pro-environmental individuals report performing eco-driving behaviours to a greater extent than less pro-environmental individuals?

As above, only Factors 1 and 2 were used to address this research question, this time looking at propensity score. Previous literature suggests that pro-environmental individuals are more likely to engage in pro-environmental behaviours (Bamberg \& Möser, 2007), and that more pro-environmental individuals report a higher frequency of performing eco-driving behaviours (Delhomme et al., 2013); regarding this relationship, results from our survey were mixed. Firstly, Factor 1 scores, those relating to general energy use attitudes, were not at all related to self-reported propensity to eco-drive, in contrast to Delhomme et al.'s (2013) findings. Factor 2 and propensity scores, on the other hand, did show a significant, moderate relationship; those scoring higher in energy conservation attitudes also reported a higher propensity to perform eco-driving behaviours. This is in contrast to Harvey et al.'s (2013) finding that energy attitudes and eco-driving are not conceptually linked; our results suggest that those who report performing energy conservation strategies to a greater extent (with all but one of the items referring to domestic or general conservation rather than travel choices) are also more likely to report performing eco-driving. Given the mixed results, however, we cannot accept our hypothesis that those with more pro-environmental attitudes will also report a higher propensity to perform eco-driving behaviours. 
4.5. Q5: Do people with greater knowledge of eco-driving also report performing it to a greater extent?

As aforementioned, Hines et al. (Hines et al., 1987; Jensen, 2002) suggested that a self-reported performance of pro-environmental behaviours is associated with a greater knowledge of available action strategies. The significant correlation between tip score and propensity score shown above lends tentative support to this assertion, though given the small effect size (Spearman's $\rho$ of just 0.14 ), strong conclusions are difficult to make. We can, therefore, only cautiously accept the hypothesis that those who are more knowledgeable of eco-driving behaviours also report a higher propensity to perform them.

4.6. Q6: How does knowledge of, and propensity to perform eco-driving behaviours vary with age and gender?

As described in the introduction, the relevant literature regarding this question is mixed; King (2011) found that older males were more knowledgeable about eco-driving, whereas Delhomme et al. (2013) found that older females were more likely to report performing such behaviours. In terms of the age question, our results suggest there are no differences across age groups, hence do not support either of these previous findings, nor allow us to accept our hypothesis that older drivers are more knowledgeable of, and more likely to report performing eco-driving behaviours.

Regarding gender, we found that males were both more knowledgeable of eco-driving behaviours, and were more likely to report performing them. This 
may be a reflection of the well-established and pervasive gender differences in car-culture (e.g. O'Connell, 1998). Although males were, traditionally, more intensive car users, the situation is changing; with more gender equality in the labour force comes intensified car use across both genders (Best \& Lanzendorf, 2005). Any scheme or programme intending to encourage eco-driving should therefore ensure that it reaches female drivers as well as male drivers.

4.7. Q7: Do those with higher levels of general education also have more knowledge of eco-driving behaviours?

This question aimed to assess whether or not Diamantopoulos et al.'s (2003) finding, that people with higher levels of education were also more knowledgeable about environmental issues, could also be extended to knowledge of eco-driving strategies. Our results suggest that it cannot; we could find no significant differences in tip score between groups of differing levels of education. We therefore reject our hypothesis that more highly educated individuals will also be more knowledgeable of eco-driving.

\subsection{Study limitations}

The first major limitation to this research is the fact that it relies on selfreports of behaviour and attitudes. In terms of environmental behaviours, some have argued that self-reports are adequate indicators of actual behaviour (e.g. Fuj, Hennessy, \& Mak, 1985; Warriner, McDougall, \& Claxton, 1984), whereas others have expressed doubts (e.g. Corral-Verdudo, 1997). When looking at driving behaviour specifically, Lajunen and Summala (2003) found that social biases (which were expected to influence self-reports) did not significantly affect 
results. Importantly, however, they did not assess actual, observed behaviour. We therefore accept this as a limitation of our study design.

Although we have attempted to place an objective value on eco-driving knowledge, any attempt to quantify such knowledge, and represent it in a single figure, is prone to inaccuracies and biases. High inter-rater reliability suggested an adequate coding scheme; however, the effects of some eco-driving behaviours are highly dependent on context, and on the intensity with which they are performed. For example, although the avoidance of harsh acceleration is universally recommended as an eco-driving practice, to accelerate too slowly can incur greater fuel consumption than positive, firm accelerations. Also, it may be the case that some respondents, when referring to 'slow driving' (an invalid tip), were actually aware that this is only a valid fuel-saving technique at high speeds, yet did not explicitly indicate this when responding (e.g. they may have assumed that this would be understood). Our categorisation scheme could not have captured these potential differences, and although we have attempted to be as objective as possible in our assessment of eco-driving knowledge (thereby arriving at a score that truly does reflect the knowledge of the individual), we accept the inability to definitively do so as a limitation of the study. We also accept as a limitation the upper limit of four eco-driving tips. This number was chosen as it replicated King's (2011) approach; however, it is quite possible that some participants would have provided more than four tips if given the opportunity.

Finally, it is important to bring to attention the limitations of the sample. First, 73.8\% of the sample held an undergraduate degree-level qualification or higher. This is far higher than the $24 \%$ found in the UK's adult population as a 
whole (Office for National Statistics, 2012). Second, the over 65 group was under-represented in our sample (at under 2\%), likely a result of the combination of the survey's web-based design, and the snowball approach to sampling. Additionally, all of our respondents indicated living in the UK; we cannot, therefore, generalise to other nationalities or cultures. As Harvey et al. (2013) demonstrated, attitudes towards eco-driving, and indeed towards the transport system as a whole, differ with nationality. How our results might differ across culture is a question that can be addressed only by future research.

\section{General conclusions}

In terms of the knowledge of eco-driving held by the public at large, there is general correspondence between the behaviours most commonly reported as having an effect on fuel economy, and those argued (in the literature) to be most influential (i.e., gear choice, and acceleration and deceleration behaviours). Furthermore, people's estimates of the potential savings that eco-driving practices can bring about are similar to those seen in the academic literature, with general consensus that eco-driving is a worthwhile practice that helps drivers to save fuel, and benefits the environment. However, overall knowledge of specific eco-driving behaviours was quite low, and the relationships between environmental attitudes and knowledge of, and propensity to perform ecodriving behaviours, although they exist, are weak. Neither pro-environmental attitudes nor a good knowledge of eco-driving behaviours was strongly linked with a propensity to perform eco-driving. Indeed, the determinants of proenvironmental behaviours are highly complex, and there exists no single framework that can fully explain the relationships between attitudes, knowledge, 
and behaviours (Kollmuss \& Agyeman, 2002); we would argue that this is also true for eco-driving specifically.

Although eco-driving on its own may appear to have a relatively minor impact on society's total energy use (when we also consider industrial, commercial and domestic domains), it is a mitigation strategy requiring almost no change to infrastructure or technology, hence is relatively inexpensive to implement, and yet can still realise around 10\% savings for the average driver (Barkenbus, 2010). To achieve widespread uptake of eco-driving will, however, require concerted effort on the part of government and industry, as well as enduser.

\section{References}

Abrahamse, W., Steg, L., Vlek, C., \& Rothengatter, T. (2005). A review of intervention studies aimed at household energy conservation. Journal of Environmental Psychology, 25(3), 273-291. http://doi.org/10.1016/j.jenvp.2005.08.002

Alicke, M. D. (1985). Global self-evaluation as determined by the desirability and controllability of trait adjectives. Journal of Personality and Social Psychology, 49(6), 1621-1630. http://doi.org/10.1037/00223514.49.6.1621

Alicke, M. D., Klotz, M. L., Breitenbecher, D. L., Yurak, T. J., \& Vredenburg, D. S. (1995). Personal Contact, Individuation, and the Better-Than-Average Effect. Journal of Personality and Social Psychology, 68(5), 804-825. http://doi.org/10.1037/0022-3514.68.5.804

Altman, D. G. (1991). Practical statistics for medical research. London: Chapman and Hall.

Arcury, T. (1990). Environmental Attitude and Environmental Knowledge. Human Organization, 49(4), 300-304.

Bamberg, S., \& Möser, G. (2007). Twenty years after Hines, Hungerford, and Tomera: A new meta-analysis of psycho-social determinants of proenvironmental behaviour. Journal of Environmental Psychology, 27(1), 14- 
25.

Barkenbus, J. N. (2010). Eco-driving: An overlooked climate change initiative. Energy Policy, 38(2), 762-769. http://doi.org/10.1016/j.enpol.2009.10.021

Barth, M., \& Boriboonsomsin, K. (2008). Real-World CO2 Impacts of Traffic Congestion. In Transportation Research Record: Journal of the Transportation Research Board, No. 2058 (pp. 163-171). Washington, DC: Transportation Research Board of the National Academies.

Beckx, C., Int Panis, L., De Vlieger, I., \& Wets, G. (2007). Influence of gear changing behaviour on fuel-use and vehicular exhaust emissions. Highway and Urban Environment, 45-51.

Best, H., \& Lanzendorf, M. (2005). Division of labour and gender differences in metropolitan car use. An empirical study in Cologne, Germany. Journal of Transport Geography, 13(2), 109-121. http://doi.org/10.1016/j.jtrangeo.2004.04.007

Birrell, S. A., Fowkes, M., \& Jennings, P. A. (2014). Effect of using an in-vehicle smart driving aid on real-world driver performance. IEEE Transactions on Intelligent Transportation Systems, 15(4), 1801-1810.

Birrell, S. A., Young, M. S., \& Weldon, A. M. (2013). Vibrotactile pedals: provision of haptic feedback to support economical driving. Ergonomics, 56(2), 28292.

Campbell-Hall, V., \& Dalziel, D. (2011). Eco-driving: Factors that determine takeup of post-test training research. TNS-BMRB report v5210046, (May).

Continental. (2015). eHorizon.

Corral-Verdudo, V. (1997). Dual "realities" of conservation behavior: Self-reports vs observations of re-use and recycling behavior. Journal of Environmental Psychology, 17(2), 135-145. http://doi.org/10.1006/jevp.1997.0048

Cronbach, L. J. (1951). Coefficient alpha and the internal structure of tests. Psychometrika, 16, 297-334.

De Vlieger, I. (1997). On-board emission and fuel consumption measurement campaign on petrol-driven passenger cars. Atmospheric Environment, 31(22), 3753-3761. http://doi.org/10.1016/S1352-2310(97)00212-4

Delhomme, P., Chapp??, J., Grenier, K., Pinto, M., \& Martha, C. (2010). Reducing air-pollution: A new argument for getting drivers to abide by the speed limit? Accident Analysis and Prevention, 42(1), 327-338.

http://doi.org/10.1016/j.aap.2009.08.013

Delhomme, P., Cristea, M., \& Paran, F. (2013). Self-reported frequency and perceived difficulty of adopting eco-friendly driving behavior according to gender, age, and environmental concern. Transportation Research Part D: Transport and Environment, 20, 55-58.

Department of Energy and Climate Change. (2015). Energy Consumption in the $U K$.

Diamantopoulos, A., Schlegelmilch, B. B., Sinkovics, R. R., \& Bohlen, G. M. (2003). Can socio-demographics still play a role in profiling green consumers? A review of the evidence and an empirical investigation. Journal of Business 
Research, 56(6), 465-480. http://doi.org/10.1016/S0148-2963(01)00241-7

Driver and Vehicle Standards Agency. (2015). The Official DVSA Guide to Driving. London: The Stationary Office.

Ecowill. (2015). The Golden Rules of Ecodriving.

Energy Saving Trust. (2015). Drive Smarter.

Evans, L. (1979). Driver behaviour effects on fuel consumption in urban driving. Human Factors, 21, 389-398.

Flamm, B. J. (2006). Environmental Knowledge, Environmental Attitudes, and Vehicle Ownership and Use.

Franke, T., Arend, M. G., Mcilroy, R. C., \& Stanton, N. A. (2016). Ecodriving in hybrid electric vehicles - exploring challenges for user-energy interaction (in press). Applied Ergonomics, 1-28.

Fuj, E. T., Hennessy, M., \& Mak, J. (1985). An evaluation of the validity and reliability of survey response data on household electricity conservation. Evaluation Review, 9, 93-104.

Harvey, J., Thorpe, N., \& Fairchild, R. (2013). Attitudes towards and perceptions of eco-driving and the role of feedback systems. Ergonomics, 56(3), 37-41.

Haslam, R., \& Waterson, P. (2013). Ergonomics and sustainability. Ergonomics, 56(3), 343-347.

Haworth, N., \& Symmons, M. (2001). The relationship between fuel economy and safety outcomes, (188), 1-67.

Hines, J. M., Hungerford, H. R., \& Tomera, A. N. (1987). Analysis and Synthesis of Research on Responsible Environmental Behavior: A Meta-Analysis. The Journal of Environmental Education. http://doi.org/10.1080/00958964.1987.9943482

Hooker, J. N. (1988). Optimal driving for single-vehicle fuel economy. Transportation Research Part A: General, 22(3), 183-201. http://doi.org/10.1016/0191-2607(88)90036-2

Jamson, H., Hibberd, D. L., \& Merat, N. (2013). The design of haptic gas pedal feedback to support eco-driving. In Proceedings of the Seventh International Driving Symposium on Human Factors in Driver Assessment, Training and Vehicle Design (pp. 264-270).

Jensen, B. B. (2002). Knowledge, Action and Pro-environmental Behaviour. Environmental Education Research, 8(3), 325 - 334. http://doi.org/10.1080/13504620220145474

King, P. (2011). AA Member eco-driver survey, (June).

Kollmuss, A., \& Agyeman, J. (2002). Mind the Gap: Why do people act environmentally and what are the barriers to pro-environmental behavior? Environmental Education Research, 8(3), 239-260. http://doi.org/10.1080/13504620220145401

Lajunen, T., \& Summala, H. (2003). Can we trust self-reports of driving? Effects of impression management on driver behaviour questionnaire responses.

Transportation Research Part F: Traffic Psychology and Behaviour, 6(2), 97- 
107. http://doi.org/10.1016/S1369-8478(03)00008-1

Lichtenstein, S., \& Fischhoff, B. (1977). Do those who know more also know more about how much they know? Organizational Behavior and Human ..., 183(3052), 159-183. http://doi.org/10.1016/0030-5073(77)90001-0

McKenna, F. P., Stanier, R. A., \& Lewis, C. (1991). Factors underlying illusory selfassessment of driving skill in males and females. Accident Analysis and Prevention, 23(1), 45-52. http://doi.org/10.1016/0001-4575(91)90034-3

Moore, D. A., \& Small, D. A. (2007). Error and bias in comparative judgment: On being both better and worse than we think we are. Journal of Personality and Social Psychology, 92(6), 972-989.

Muñoz-Organero, M., \& Magaña, V. C. (2013). Validating the Impact on Reducing Fuel Consumption by Using an EcoDriving Assistant Based on Traffic Sign Detection and Optimal Deceleration Patterns. IEEE Transactions on Intelligent Transportation Systems, 14(2), 1023-1028.

Nunnally, J. C. (1978). Psychometric theory. New York: McGraw-Hill.

O'Connell, S. (1998). The Car and British Society: Class, Gender and Motoring, 1896-1939. Manchester, UK: Manchester University Press.

Office for National Statistics. (2012). Measuring National Well-being, Education and Skills. London.

Schmitt, N. (1996). Uses and abuses of coefficient alpha. Psychological Assessment, 8(4), 350-353. http://doi.org/10.1037/1040-3590.8.4.350

Sivak, M., \& Schoettle, B. (2011). Eco-driving: strategic, tactical, and operational decisions of the driver that improve vehicle fuel economy, (August), 19. Retrieved from http://141.213.232.243/handle/2027.42/86074

Stanton, N. A., McIlroy, R. C., Harvey, C., Blainey, S., Hickford, A., Preston, J. M., \& Ryan, B. (2012). Following the cognitive work analysis train of thought: exploring the constraints of modal shift to rail transport. Ergonomics, (September), 37-41.

Staubach, M., Schebitz, N., Köster, F., \& Kuck, D. (2014). Evaluation of an ecodriving support system. Transportation Research Part F: Psychology and Behaviour, 27, 11-21.

Stern, N. (2006). Stern Review: The Economics of Climate Change. Summary of Conclusions.

Streiner, D. L. (2003). Starting at the beginning: An introduction to coefficient alpha and internal consistency. Journal of Personality Assessment, 80(1), 99103.

Svenson, 0. (1981). Are we all less risky and more skillful than our fellow drivers? Acta Psychologica, 47, 143-148.

Thatcher, A. (2012). Green ergonomics: definition and scope. Ergonomics, (September), 37-41.

The AA. (2015). Eco-driving advice.

Transport, D. for. (2015). Road traffic estimates: Great Britain 2014, 2014(December). Retrieved from 
https://www.gov.uk/government/uploads/system/uploads/attachment_da ta/file/428671/annual-road-traffic-estimates-2014.pdf

Trommer, S., \& Höltl, a. (2012). Perceived usefulness of eco-driving assistance systems in Europe. IET Intelligent Transport Systems, 6(2), 145. http://doi.org/10.1049/iet-its.2011.0154

van der Voort, M., Dougherty, M. S., \& van Maarseveen, M. (2001). A prototype fuel-efficiency support tool. Transportation Research Part C: Emerging Technologies, 9, 279-296.

Wada, T., Yoshimura, K., Doi, S., Youhata, H., \& Tomiyama, K. (2011). Proposal of an eco-driving assist system adaptive to driver's skill. In 14th International IEEE Conference on Intelligent Transportation Systems (pp. 1880-1885). Washington, DC.

Warriner, G. K., McDougall, G. H. G., \& Claxton, J. D. (1984). Any data or none at all? Living with inaccuracies in self-reports of residential energy consumption. Environment and Behavior, 16, 503-526.

Waters, M. H. L., \& Laker, I. B. (1980). Research on fuel conservation for cars. Report No. 921. Crowthorne, England.

Young, M. S., Birrell, S. A., \& Stanton, N. A. (2011). Safe driving in a green world: a review of driver performance benchmarks and technologies to support "smart" driving. Applied Ergonomics, 42(4), 533-9. 